\title{
Technologies, Culture, Work, Basic Income and Maximum Income
}

\author{
Alan Cottey \\ University of East Anglia, Norwich NR4 7TJ, UK \\ e-mail: a.cottey@uea.ac.uk
}

\begin{abstract}
Radical changes of our cultural values in the near future are inevitable, since the current culture is ecologically unsustainable. The present proposal, radical as it may seem to some, is accordingly offered as worthy of consideration. The main section of this article is on a proposed scheme, named Asset and Income Limits, for instituting maxima to the legitimate incomes and assets of individuals. This scheme involves every individual being associated with two bank accounts, an asset account (their own property) and a holding account (held in escrow). Other parts of the advocated change of economic landscape are a radically different understanding of the concept of work, and the introduction of a basic income. The roles of technology and culture, in creating both the opportunities and the obstacles to a transformation of society, are discussed. Non-monetary, non-convertible rewards for exceptional contributions to society are described. The scheme enhances freedom, being neutral in relation to many other value systems, such as the secular/sacred spectrum. The qualitative versus quantitative dichotomy is addressed and it is concluded that the most that can be said of a just and sustainable society that has yet to be created is that the maximum income should be no more than one order of magnitude greater than the basic income, that is $\sim 10$ times at the most. Incentives for profitable employment would still be sufficient and paying the basic income out of taxes on sales and/or non-basic income would be feasible.
\end{abstract}

Keywords maximum income; basic income; sustainability; work; technology; culture 


\section{Introduction}

The coming period must bring order to our minds, our production, our feeling, our economic and social development. It has to bridge the gap that, since the onset of mechanization, has split our modes of thinking from our modes of feeling.

Giedion $1948 \mathrm{p} \mathrm{v}$

Sixty-four years since Siegfried Giedion wrote these words, the disorder and fragmentation of our culture is as problematic as ever (Barber 2008, Battersby et al 2012, Beddington 2009, Brown 2002, Collins 2012, Cottey no date, Daly no date, de Angelis 2007, Douthwaite 1999, Duchrow and Hinkelammert 2004, Forbes no date, Kempf 2008, Korten 2001, Murphy 2011, Pizzigati 2004, Rifkin 2000, Robertson 2012). The present article aims to contribute to finding the needed order and coherence. Its core section is on Maximum Income. Two other sections, on Work and on Basic Income, go with it to make an economic package. If the recommendations (or something like them) became the norm, they would be part of the foundation of an orderly and coherent culture. This requires a spurt of cultural evolution, something which is not as far-fetched as conventional thinkers imagine. For the planet's ecology is already stressed and mighty changes are in train. This rapid evolution may take the form of decay - not of this or that empire, as happened frequently in the past, but of human civilisation globally. It is nevertheless important to hold onto hope, for without hope we will not even attempt the intellectual and practical work needed to avoid such a bad outcome. The task is nothing less than a change of human values, from desires to dominate other humans, life forms and inorganic materials on the earth, to desires to cohabit this planet. The recent reaction against consumerism - see for example Michael Sandel's What Money Can't Buy (2012) - may be the beginnings of a sea-change. Therein lies a ray of hope, and a basis for strategic optimism.

I present these three key sections (Work, Basic income, Maximum income) after several brief preliminary sections outlining the links with the aspects of this themed issue of AI \& Society - technology, culture and international stability.

\section{International stability}

AI \& Society is celebrating its 25th anniversary and International Stability, Technology and Culture is a technical committee, formed (under a different name) about thirty years ago (IEEE global history network, no date), of the International Federation of Automatic Control. The cultural and political understandings and concerns associated with the terms International and Stability have changed over these last few decades. I will outline my understanding of those changes which relate to the present paper.

\subsection{International and global coexist}

In the 1980s and preceding decades the Cold War with its baroque nuclear arsenals were matters of intense concern. Further, it was generally taken for granted that the principal actors in world political affairs were nation-states and the associated international institutions (see for example Russett and Starr 1989). Now, the term international is generally used in a context that is broader in two ways. Global thinking, especially of global environmental effects has come centre-stage; and the importance of non-state actors, especially transnational corporations and their champions, are now more adequately recognised (as in for example Korten 2001). Doug Brown asserts a convergence between nation-states and corporations.

At the top of the [culture] pyramid are corporations. They are at the peak only because they are the most visible and wield tremendous power in today's global economy. Most would agree that they are the biggest and most influential players in the economic arena, notwithstanding the nation-state. Yet many would argue that the nations of the world today are the corporations. Their preoccupation is with controlling people and markets.

Brown 2002 p4

\subsection{Stability and change}

Here also there is a development of thinking over the last few decades. In the 1960s to 1980s - to bracket and characterise a period schematically - even the stability of an unjust status quo was preferable to instability leading to nuclear war. Today it is more widely recognised that the stability question is broader than the stark dichotomy of the Cold War period. Simple stability is in any case unattainable; change occurs on all time-scales (Cottey 2012). The brief period when humans thought they might be in control of the natural world and of their own destinies is at an end. This is clear to those who understand the prospect of a 'perfect storm' (Beddington 2009) of environmental and cultural challenges. 


\section{Technologies and Culture}

Because of this concern with relative stability, in a setting of demanding change, and a desire for historical perspective, I refer here to technologies in the plural. Space does not permit a panoramic view but we can at least compare the present time, of new potent technologies whose outcomes we know not, with one historical period which has some similarities to the present time. I refer to the early nineteenth century industrialisation in Britain. The inventions of the previous century had become ripe for use on a massive scale - and they were so used. Those were times of golden opportunity for bold but ruthless engineers and entrepreneurs. But the social consequences were profound disruption of the rural ways of life of millions of workers and their families. Those ways of life, hard but at least with some longevolved mutual support structures, were replaced by unfamiliar, atrocious urban living conditions, with slum housing and cruel working conditions of the most appalling kind. All this is well known (Engels 1969, Engler 1995) but I mention it in order to re-sensitise ourselves and also to propose some similarity (and many differences as well, of course) with the present times (considered globally). The conditions of the propertyless in Britain reached a nadir at that time and the consciences of many empowered people, as well as the struggles of the poor for the right to a decent existence, gradually won reforms. These reforms were reactions to terrible conditions created by ruthless or unthinking exploiters. The social conditions at the peak of progressive reforms, roughly two-thirds of the way through the twentieth century (since when there has been a decline) no doubt seemed a utopian dream to many in the early nineteenth century.

Today, information technology and biotechnology can be considered roughly analogous to early nineteenth century mechanical technology in that they have become mature enough to permit society-transforming applications. Human values, customary laws and formal laws have not kept up with the new technologies. Most people, while happily accepting the new offerings of a growth-oriented capitalism, have little awareness of the associated global social and ecological changes (Korten 2001, Rifkin 2004).

Although it is generally understood that we live in times of rapid technological change, it is not universally accepted that global ecological change is occurring. Many people actively deny anthropogenic climate change, and still more simply ignore the problem. Yet the change is remarkable, on historical and archaeological time-scales. It is producing and will produce profound social changes. Intellectual responses to all this should embrace simultaneously a range of time-scales (Cottey 2012). To adapt an aphorism attributed (O'Reilly 2003) to Ray Kurzweil -

An idea does not have to make sense in the world in which it is proposed. It has to make sense in the world in which it will be used.

\subsection{Culture and social invention}

We live in times of vibrant technological inventiveness. This is accepted but it is not noted that we also live in times of unusual timidity in respect of progressive social inventions. It would appear that those who hold economic and political power have an interest in the status quo and use their influence to maintain it. If our current human culture were as bold and innovative in social invention as it is in technological invention, there would be a social ferment, a plethora of ideas proposed for addressing all questions surrounding the big one - how to achieve a just and sustainable world. One of the key principles supporting my understanding of a just and sustainable world is every human must and can have ready access, essentially unqualified and by right, to the means of living a sufficient and dignified life. I discuss this further in the section on Basic income.

In a socially bolder culture, ideas would be debated vigorously and small-scale experiments would be conducted in their millions. To be sure, there are visionaries with ideas and those who try new ways. They do their best but, in socially conservative and reactionary times, their contributions remain at the margin. Radical ideas for rejecting the current neo-liberal materialism and crudeness, and finding a just and sustainable way of living, are numerous enough. They can be found in many of the references I cite in this paper but are known to only a small minority. Mainstream thought has not yet broken free of the neo-liberal agenda and instead proposes such small adjustments as

-- ad-hoc aid for the poor (frequently offered grudgingly, in meagre amounts, demeaningly; and sometimes even siphoned off by corrupt intermediaries)

-- small reductions in radically unsustainable plans for growth

-- programmes for the development of sustainable technologies which are tiny compared with the mainstream programmes, which are aimed at maintaining or accelerating the growth of economically powerful established technologies.

The point of these remarks is to prepare the ground for proposing a new kind of economy. It involves a radical turning away from neo-liberal economics (Duchrow and Hinkelammert 2004, Engler 1995) and, instead, putting people before profit. The proposal is to connect three economic ideas which could together form a major element of a just and 
sustainable human culture. This new economy differs from current economic thinking in relation to the individual in three ways. I discuss these under the headings Work, Basic income and Maximum income.

\subsection{The quantitative and the qualitative}

Conventional economics is saturated with numbers and a filtered selection of these enter political debate and a selection of these are presented in the mass media. The young, through education, and adults, through the mass media, receive a world-view framed by these selections. In this way a wide public never hears of ideas which come to grips with the current and historical conditions and the real options, positive and negative, for the future. Or, if they do hear of such ideas, they reject them out-of-hand as utopian.

No merely quantitative change can turn our current dysfunctional culture into one that is functional. Qualitative changes are necessary. After a radically different culture had existed for some time, it might be possible, if that were desirable, to conduct research developing new concepts susceptible to quantification and measurement. If so, these measures would be quite different from the current measures like Gross Domestic Product and the current attempts to quantify, or at least to rank, well-being.

For these reasons I eschew numbers in the following sections. Rather, I focus on qualitative ideas (with a brief foray into the semi-quantitative); on arguments why they (or something like them) could be part of a just and sustainable culture; on why the ideas fit together; and on why modern technology renders ideas like these feasible. The essential condition remains however a profound change of our cultural values.

\section{Economics for the common good}

We can take nothing for granted in the rocky times ahead but, maintaining strategic optimism and thinking about positive possibilities, I will assume that, in some society in the putative just and sustainable future, there is a money system and an institution, such as a state or a local government, competent to maintain a level of just and sustainable use of money. Money is a most wonderful invention but the uncritical development of the money system is the root of two great evils. One is unlimited accumulation, which I will discuss in the section on Maximum income. The other is money's almost unlimited convertibility which I discuss forthwith ...

\subsection{Money and the limits of convertibility}

By its nature money has to be convertible, that is, a means of exchange (though money fulfils other roles as well, notably, as a means of accounting, as a means of storage and as interest-bearing capital; see Douthwaite 1999). But there are limits to the convertibility. There are indeed, in formal law and in custom, more limits than most people notice, notwithstanding the neo-liberal trend which has been taken to an extreme in the USA and is exposed in Sandel's What Money Can't Buy (2012).

A drastic curtailment of the convertibility of money will have to be accepted and internalised in the values of society and not just enshrined in laws that legions of lawyers and accountants are paid to circumvent. This curtailment is important for all of the next three sections, on Work, on Basic income and on Maximum income. There will be a ringfence around benign (lawful, socially acceptable and sustainable) uses of money. Malign uses (such as excessive pollution rights, bribery and unlimited accumulation) must become socially beyond the pale and not merely technically unlawful. Rationing, currently a dirty word, must become accepted in respect of many scarce resources. It is remarkable how easily, in time of total war, governments are able to impose rationing, and how readily - notwithstanding an inevitable degree of black-marketeering - the rationing is accepted by the public as necessary.

It is meaningless to attach figures, at the present time, to a proposed economy which will be qualitatively different from the present economy or indeed to any economy of which we have historical knowledge. There may be no dominant currency but rather a number of exchange media, not inter-convertible, or convertible only with restrictions. Many important resources and goods may be taken entirely out of money economies, by rationing. And, as discussed in the next section, much useful activity is done out of solidarity or love and has no monetary equivalent.

\subsection{Work}

It is now time to examine one of the most misused words in general discourse and also in technical discourse - work. I come straight to the point and assert that a large part of what is generally called work is not work, if by that word we mean activity useful in sustaining a good life. Further, a large part of such useful activity is not, in general discourse, counted as work. What activity is necessary or useful? First, something which many spiritual teachers have known since antiquity to be fundamental - breathing. In case this should not seem like work, consider two cases, one a new- 
born baby, the other a sick person with a respiratory problem. The baby does not wait for someone to help it, although in practice some help is usually forthcoming; it does for itself what it can - it hollers. The sick person, likewise, may likely have help from others, but still, himself or herself, does what is possible and in this case it clearly is work, hard work. Then everyone needs food and drink and they, including the baby, look after themselves as well as they can but are helped by others, people who care not only for themselves but also for others. All of these actions are of little or no account to a conventional economist but they are among the most fundamental actions that sustain a good life. I could continue but the point should be obvious enough.

Now we turn to what normal discourse calls work. It is generally paid employment, that is, selling one's labour. Normal discourse also includes self-employment and the management of others (a boss's own employees) - 'we all work today, you know'. I assert that a large part of these kinds of work is unnecessary and in many cases even acts against the achievement and maintenance of a good life for all. Much of this work is aimed against competitors and against laws which try to ameliorate the worst excesses of anti-social profiteering. There is also an army of people managing other people so as to maintain a grossly inefficient culture of employment and unemployment. Further, those who obtain one should not use the word earn - the largest incomes are among those who do the greatest harm, by obstructing positive change and by their central involvement in the most pernicious practices, notably speculation on a gigantic scale. Meanwhile, many others are not even able to sell their own labour, even at a low price, and suffer multiple disadvantages.

In case the claim that most so-called work is useless or even harmful should be thought an exaggeration, I point out that not much heavy or repetitive work has to be done by humans (Burke and Rumberger 1987, passim). This situation has existed for half a century at least. There have long been no technical reasons why most heavy and repetitive work should not be done by machines and computers. The obstacles to achieving this situation are cultural and have long have been so. There is, to be sure, need for work by humans, and it includes some healthy physical activity. The most needed work requires application and courage but only a small part of it is conventional employment. Apart from the caring for one self and others, there is a great need for thought, imagination and experiment (personal, domestic and political) in transcending the current grey culture and taking full advantage of the possibilities before our noses. A radical revision of what is meant by work would render the following two proposals (Basic income, Maximum income) entirely practical. The objection 'all very nice but completely unaffordable' is grounded in business-as-usual economics and is irrelevant. With the rational use of machines and computers, the abolition of structural unemployment, and the sweeping away of great swathes of bureaucracy - not needed in a just and sustainable society - all necessary public provisions, including basic income, could be funded through fairly modest taxation.

\subsection{Basic income}

Basic income and its variations have been proposed in different ways and under various names, including Citizen's Income and Negative Income Tax (Ackerman, Alstott and van Parijs 2006, Atkinson 1995, Citizen's Income Trust (no date), Raventós 2007, Roberts 1982, Walter 1989). I shall start by proposing that the most important part of Basic income is not a precise definition but a fundamental principle which will underly any civilised modern society

every human must and can have ready access, essentially unqualified and by right, to the means of living a sufficient and dignified life.

In relation to basic income my use here of 'unqualified' is standard and means that the income is paid to every person -- regardless of how much they may possess by way of other income and of assets

-- regardless of whether they attempt to gain other income

-- and regardless of the person's domestic arrangements.

This makes basic income simple to administer but the more important point is that it gives a basic right to all in a civilised society. The word 'essentially' does not appear in most definitions of basic income. By inserting it in the principle above I indicate that the basic income is paid directly to every individual competent to handle his or her personal affairs. Those not competent in this way (children, the demented, some others) will have a guardian to whom the basic income will be paid and who will administer it on the ward's behalf. Obviously, determining the general rules and making the decisions on individual cases may be difficult and contentious but these are only the same difficulties as exist in society today, as for example when enduring power of attorney has to be decided. 


\subsection{Maximum income}

The other great evil associated with money is unlimited accumulation. Today, in 2012, there should be no need to labour the harmful nature of unlimited accumulation. Excesses are news. They are bemoaned in every newspaper. Yet these complaints in the mass media and in popular discourse rarely lead to constructive suggestions. More extensive analyses of the facts and problems can however be found in, for example, Battersby et al 2012, Brown 2002, Collins 2012, Cottey no date, Duchrow and Hinkelammert 2004, Engler 1995, Forbes no date, Kempf 2008, Pizzigati 1992, Pizzigati 2004, Rifkin 2000. Currently most states allow their citizens unlimited accumulation, a principle set out explicitly by Locke (1690) and endorsed by the bourgeoisie ever since. Of this principle, C B Macpherson commented the whole [of Locke's] theory of property is a justification of the natural right not only to unequal property but to unlimited individual appropriation.

Macpherson 1962 p 221

Maximum income has attracted even less attention than basic income. Nevertheless, numerous ideas of this kind have been proposed. Sam Pizzigati has written, in Greed and good: understanding and overcoming the inequality that limits our lives (2004), an encyclopaedic survey of proposals and their context, and has also written an earlier account (1992) of his own ideas for a ten times rule. He writes

For the moment, let's be arbitrary. Let's set our maximum wage at ten times the minimum.

Pizzigati 1992 p77

Many other proposals are either brief asides or numerical proposals as may be seen from Pizzigati's survey (2004). I am arguing in the present article, especially in the section 'The quantitative and the qualitative', that the essential factor is a profound change of values, sufficient to transform economic thinking to the extent that quantification is not yet possible. I will outline some aspects of the proposal Asset and Income Limits (AIL), which is described more fully in Cottey (no date). I chose this title as being an accurate description, avoiding vaguer or inappropriate terms like wage, salary, bonus, wealth, riches. (Ironically, Asset and Income Limits means in the USA something almost contrary to my meaning. Rather than limiting the affluent, the term is used in relation to means-tested programs which debar all but the relatively poor from social benefits, notably Medicaid.)

A key idea of Asset and Income Limits is that it does not operate via redistributive taxation. In the principal currently existing economies, redistribution usually saves those without property and unable to sell their labour from the worst extremes of destitution. Quite apart from the criticisms that redistributive taxation is bureaucratic and largely evaded by the rich ('only little people pay taxes') is a more fundamental objection. The huge income and accumulated assets of a plutocrat are, in the conventional Lockean model, legitimate. It is mine. How dare they, the government, take away my money and then spend it, or more probably waste it, in ways they decide?

The starting point of the Maximum income (and assets) for individuals idea is that unlimited accumulation is a wholly anti-social concept. The huge accumulations which occur today should be de-legitimised. They should be unacceptable according to civilised human values, customary law and formal legislation.

\subsubsection{How the AIL scheme could function}

In a practical AIL scheme it must be impossible for an individual legitimately to acquire assets or income beyond the limits that apply to him or her. This condition can be met with a scheme of asset and holding accounts. Each person, of whatever age, is personally linked with two basic bank accounts, an asset account and a holding account. The asset account records all the property of the individual (or their guardian, just as in the Basic income case), which he or she may trade, invest or spend as desired, subject to restrictions imposed by various laws (such as indeed exist now). People may disperse their assets in various forms and in various subsidiary accounts. Thus freedom to invest in ways appropriate to the individual is preserved. The new feature is that the total income and expenditure of an individual must be accurately reflected in the asset account. AIL is applied by two constraints on the individual's asset account ...

-- the total value of the asset account can never exceed that person's asset limit

-- the inflow (that is, the sum of all earned and unearned income) to the asset account cannot exceed in any accounting period the income limit that applies to the individual.

All temporary excess income that an individual receives is diverted into the holding account, which is 'in the name of' the individual but not, at this stage, the property of that individual. The asset account is always up-to-date and (the balance of) any new income which would take either the asset account or the annual income over the applicable limit would go directly into the holding account. 
Funds in the asset account are the property of the individual but funds in the holding account are not. They belong temporarily to the escrow institution. This is a trustworthy institution, capable, as well as humanly possible, of administering the holding funds fairly. The escrow institution would have a democratic board and management structure, and it would be independent of the rest of the AIL administration and of the government treasury department. Funds in a holding account 'in the name' of an individual would be held by the escrow institution for a year or in some cases for several years so that every citizen receives, in due course, any funds which would not bring them over their limits, now calculated as an average over several years. Funds which are left over, that is, are long-term excesses, go into a social, collective account. This latter account might be part of a government revenue department but should not be called a tax department. AIL is nothing to do with taxes.

Here is an example of the use of the holding account: Mrs Atherlimit dies and bequeaths her estate to her son, Mr Goodjobwithyoungfamily, who has income fairly near the limit but few savings. The rules permit a person in such circumstances to receive a substantial sum, and have it considered equivalent to income spread over several years, provided it is a genuinely exceptional income. Time will be needed to allow Mr Goodjobwithyoungfamily's accountant to negotiate, with the escrow institution and with interested parties, the way of dealing with this case which is best for Mr Goodjobwithyoungfamily, while remaining within the AIL rules.

\subsubsection{Benign, Non-convertible Rewards}

A common justification of unlimited accumulation and objection to high tax rates is that certain people are specially talented and hard-working and contribute greatly to society. Any attempt to reduce the current levels of inequality will be counterproductive. Various arguments are deployed - the tax revenue will decrease, the talented will emigrate, they will lack motivation. I find all of these arguments spurious, for reasons that emerge throughout this paper and in many of the references. The neo-liberal era is nearing an irreversible change, which may be a cultural collapse, this time not of some empire but of a global system, or it may be something like the Great Turning (Johnstone no date, Korten 2006, Macy and Brown 1998). The latter will be a culture in which cooperation (Pagel 2012), more than competition, is recognised and valued.

Currently, 'wealth' as generally understood - that is, sum of assets convertible into money - has, in the upper range, a largely symbolic character. What rich people really want is approbation and status. It is likely to remain so. This need not be a problem. All that is needed is that everyone be restrained from activities that harm the environment and other people. A sustainable world must be much more just than ours but it need not be strongly egalitarian. Talented, determined or lucky people might have much more glamour, or respect, or fame, or honour, or power than other people. In Cottey (no date) I describe some the ways in which, AIL notwithstanding, some people could be privileged. Here is a brief summary of the relevant section ...

-- Awards Honours and Prizes for Merit: See, for example, English 2005. There is already an enormous number of such awards, etc, as an internet search quickly reveals, and they are taken very seriously.

-- Celebrity: I suggest that celebrity is important for human society and fulfils a non-trivial need, namely for personalities that all of us in a society feel we know, although they are in reality distant from us. They bring us together, albeit superficially.

-- Luck: gambling attracts many people. It could continue under AIL. Huge, convertible prizes would no longer be possible, but significant alternatives remain.

-- Power: for some, this is reward in itself.

-- Services: people making especially important contributions to society could concentrate their talents and commitment and not spend much time on the many routine tasks of normal everyday life.

-- Custody of treasures: rewards such as custody of a renowned painting can be devised.

All of these rewards will, in a just culture, be administered with more integrity than is currently the norm.

\section{Pulling these ideas together. Can we create a sustainable culture?}

If we pull the ideas of this article together, we envision a convivial society in which people's lives are simple, restful and fulfilling. Machines and computers do most of the heavy and repetitive work. Humans still have a significant amount of work to do. One side of this is caring for ourselves and others. Another side is intellectual and moral - the development of wisdom, defined by Ronald Barnett and Nicholas Maxwell as the capacity to realize what is of value in life, for oneself and others, thus including knowledge and technological know-how, but much else besides.

Barnett and Maxwell 2008 p viii Such wisdom needs to be developed and continuously modified by everyone; it is not the preserve of 'intellectuals'. The new world will be not utopia, nor will there ever be a static society. Problems will abound, not least those emerging 
from rising expectations once the gross injustice and unsustainability of the present economy is overcome.

\subsection{Freedom}

Some may suppose that this model is associated with some political philosophy, possibly socialism. Assuming this may be understandable, but a mistake nonetheless. I offer this model as a practical response to our present problems, independent of numerous dimensions of political and cultural ideology. The social model

-- might have a mainly secular or a mainly sacred orientation

-- might be spiritual or materialistic (in the ontological sense)

-- could be compatible, in some areas, such as the arts, with a high degree of individualism

-- its government might conform to any of several models (by the people, by a parliament of elected representatives, by a party elite, etc) or a combination of these

-- its legislative and judicial systems might similarly conform to any of several models, or to combinations

-- true, the culture could not be capitalist in the traditional mode, but it could have an element of capitalism with no large owners or shareholders and strictly limited interest on capital. There could be free markets, within overriding constraints set by the requirements of justice and sustainability

-- it necessarily places a specific restraint on inequality between people, but this is far short of a general egalitarianism. Some people could be privileged (by luck, talent or effort) as long as the privileges did not harm the environment and were not tradable.

In sum, the model is liberal in the sense of being open-minded and tolerant in relation to a wide range of economic, political and cultural patterns.

\subsection{A qualitative (or semi-quantitative) response to the question 'what is the maximum income?'}

No quantities regarding maxima of individuals' income and assets can be stated, except arbitrarily, because the proposal will exist in a presently unknown context. Still, one qualitative limit can be stated. The needed change of values will be incomplete, with reactionary opinion co-existing with sustainable values. Many people will strive to reach the maximum. Therefore the maximum must be fairly low and not a high maximum timidly set to appease those who hanker after the old regime. In view of the overload of the planet's ecology and high human population, an upper limit for a possible maximum income, compatible with global justice and sustainability, is, in my opinion, one order of magnitude greater than the basic income, that is, a factor $\sim 10$. A cooperative society will be simpler than the present one. Greater use will be made of goodwill, trust and voluntarism. Some kinds of work analogous to what exists now will need significant effort. But the present vast amount of complex regulation and efforts put into escaping regulation will be largely absent. In this milieu, the basic income will be adequate for a sufficient and dignified life but still the great majority of people will have energy, ability and desire to do profitable work, bringing in further income. It will not be like the present oppressive wage system even though many may choose to sell some of their labour. A maximum income of one order of magnitude greater than the basic income will provide a very comfortable, even quite luxurious, existence for those who enter into the spirit of the new world. A tax on sales and/or non-basic income will fund the basic income and other government expenses needed in a simple, efficient and fulfilling economy. With this one order of magnitude range, the taxation need not be onerous, given that most of today's expenditures will be unnecessary. Of course, global justice and sustainability will not come about quickly, even if the current global economic model collapses or is decisively rejected. So we should consider smaller societies which may put models into effect with some of the features discussed here. Indeed, on the very small scale, some intentional communities have done so already. Therefore models which are more egalitarian, but not totally flat, may also be considered, in which the ratio between maximum income and basic income is smaller, perhaps half an order of magnitude, that is, $\sim 3$, or 'a few'. In such cases, the sales and non-basic income tax rates will need to be higher, the fraction of people adding to their basic income will need to be high (which it probably will be in every case) and the society will have a high level of solidarity.

\subsection{Cooperation}

The ideas presented in this paper (Work, Basic income, Maximum income) will seem utopian from an individualistic, neo-liberal point of view. There are however other aspects of our culture. Sandel (2012) examines them from a philosophical point of view in What Money Can't Buy: the moral limits of markets. In a lifetime's work on Common Pool Resources, Elinor Ostrom developed, with others, an empirical mass of data and then theoretical ideas showing 
that individualism has not swept the world. Even in the USA cooperative management of common resources is widespread. She "present[s] empirical evidence of successful and unsuccessful efforts to govern and manage such resources" (p2 of Ostrom 1990). Dolšak and Ostrom have edited (2003) a collection of papers on The commons in the new millennium. Poteete, Janssen and Ostrom (2010) have drawn together much of this work and applied it, in a reflexive manner, to multiple method collaborative social research itself. Perhaps the many cooperations which keep human society functioning will be too little and too late, but this is not certain. It is worth holding on to strategic optimism and trying to turn around the current disastrous version of progress.

'In dreams begins responsibility.'

epigraph quoted by W B Yeats; Albright 1992 p148

\section{Acknowledgments}

I acknowledge with thanks comments from T Belton, D Iseli, K Lam, P Lanyon, P Le Mare, J Nelson, F Oeser, P Pickbourne and M Torry.

\section{References}

Ackerman B, Alstott A, van Parijs P (2006) Redesigning distribution: basic income and stakeholder grants as alternative cornerstones for a more egalitarian capitalism. Verso, London

Albright D, editor (1992) W B Yeats: the poems. Dent, London

Atkinson A B (1995) Public economics in action: the basic income/flat tax proposal. Oxford University Press, Oxford

Barber B R (2008) Con\$Umed: how markets corrupt children, infantilize adults, and swallow citizens whole. Norton, New York

Barnett R, Maxwell N (2008) Wisdom in the university. Routledge, London

Battersby S, Else L, George A, Norton M I, Pearce F, Rogers D (2012) The Age of Inequality. New Scientist 215 $(2875): 37-45$

Beddington J (2009) The perfect storm. Government Office for Science http://www.bis.gov.uk/goscience/news/speeches/the-perfect-storm accessed 13 September 2012

Brown D (2002) Insatiable is not sustainable. Praeger, Westport, CT

Burke G, Rumberger R W, editors (1987) The future impact of technology on work and education. Falmer Press, London

Citizen's Income Trust (no date) citizensincome.org/ (Contains much downloadable material.) accessed 13 September 2012

Collins C (2012) 99 to 1: how wealth inequality is wrecking the world and what we can do about it. Berrett-Koehler, San Francisco

Cottey A (no date) Asset and income limits. http://www.uea.ac.uk/ c013/ail/ail.html accessed 13 September 2012

Cottey A (2012) Logarithmic time: its role in current culture and education. Policy Futures in Education 10(2):234-236

Daly H (no date) Eight fallacies about growth. http://steadystate.org/eight-fallacies-about-growth/ accessed 13 September 2012

de Angelis M (2007) The beginning of history: value struggles and global capital. Pluto, London

Dolšak N, Ostrom E (2003) The commons in the new millennium: challenges and adaptations. MIT Press, Cambridge, MA

Douthwaite R (1999) The ecology of money. Green Books, Totnes, UK 
Duchrow U, Hinkelammert F J (2004) Property for people, not for profit. Zed Books, New York

Engels F (1969) The condition of the working class in England: from personal observations and authentic sources. (With an introduction by E Hobsbawm.) Panther, St Albans, UK. First published, in German, 1845. Many other editions exist including from Project Gutenberg http://www.gutenberg.org/ebooks/17306

Engler A (1995) Apostles of greed: capitalism and the myth of the individual in the market. Pluto, London

English J F (2005) The economy of prestige: prizes, awards, and the circulation of cultural value. Harvard University Press, Cambridge, MA

Forbes (no date) The world's billionaires. Forbes. http://www.forbes.com/billionaires accessed 13 September 2012

Giedion S (1948) Mechanization takes command: a contribution to anonymous history. Oxford University Press, Oxford

IEEE global history network (no date). Obituary of Harold Chestnut. http://www.ieeeghn.org/wiki/index.php/Harold_Chestnut accessed 13 September 2012

Johnstone C (no date) Great turning times. http://greatturningtimes.org accessed 13 September 2012

Kempf H (2008) How the rich are destroying the earth. Green Books, Totnes, UK

Korten D C (2001) When corporations rule the world, 2nd edition. Berrett-Koehler, San Francisco

Korten D C (2006) The great turning: from empire to earth community. Berrett-Koehler, San Francisco

Locke J (1690) Second treatise of government. Project Gutenberg. http://www.gutenberg.org/ebooks/7370 accessed 13 September 2012

Macpherson C B (1962) The political theory of possessive individualism. Oxford University Press, Oxford

Macy J, Brown M Y (1998) Coming back to life: practices to reconnect our lives, our world. New Society Publishers, Gabriola Island, BC, Canada

Murphy R (2011) The courageous state: rethinking economics, society and the role of government. Searching Finance, London

O'Reilly T (2003) Open source paradigm shift. http://oreilly.com/tim/articles/paradigmshift_0504.html accessed 13 September 2012

Ostrom E (1990) Governing the commons: the evolution of institutions for collective action. Cambridge University Press, Cambridge

Pagel M (2012) Wired for culture: the natural history of human cooperation. Allen Lane, London

Pizzigati S (1992) The maximum wage: a common-sense prescription for revitalizing America - by taxing the very rich. Apex, New York

Pizzigati S (2004) Greed and good: understanding and overcoming the inequality that limits our lives. Apex, New York

Poteete A R, Janssen M A, Ostrom E (2010) Working together: collective action, the commons, and multiple methods in practice. Princeton University Press, Princeton

Raventós D (2007) Basic income: the material conditions of freedom. Pluto, London

Rifkin J (2000) The age of access: the new culture of hypercapitalism, where all of life is a paid-for experience. Tarcher/Putnam, New York

Rifkin J (2004) The end of work: the decline of the global labor force and the dawn of the post-market era. Revised 
edition. Tarcher/Penguin, New York

Roberts K (1982) Automation, unemployment and the distribution of income. European Centre for Work and Society, Maastricht

Robertson I (2012) The ultimate high. New Scientist 215(2872):28-29

Russett B, Starr H (1989) World politics: the menu for choice, 3rd edition. Freeman, New York

Sandel M J (2012) What money can't buy: the moral limits of markets. Allen Lane, London

Walter T (1989) Basic income: freedom from poverty, freedom to work. Marion Boyars, London

$$
\text { --- END --- }
$$

[Author's manuscript (postprint) of AI \& Society: journal of knowledge, culture and communication (2013). Special Issue: International systems stability, culture and technology. DOI: 10.1007/s00146-013-0480-0 ] 